\title{
The clinicopathological features of epithelioid undifferentiated sarcoma with TFE3 amplification: one case report and literature review
}

\section{Yuejiao Lang}

the first affiliated hospital,Sun Yat-sen University

\section{Xiaojuan Li}

Yunchen central hospital

\section{Shaoyu Chen}

Guangzhou LBP medical technology Co. Ltd

\section{Pei Xiang}

the first affiliated hospital, Sun Yat-san University

Anjia Han ( $\sim$ hananjia@mail.sysu.edu.cn )

The First Affiliated Hospital,Sun Yat-Sen University

\section{Case Report}

Keywords: epithelioid undifferentiated sarcoma, TFE3, gene amplification, case report

Posted Date: August 4th, 2020

DOl: https://doi.org/10.21203/rs.3.rs-52799/v1

License: (c) (i) This work is licensed under a Creative Commons Attribution 4.0 International License. Read Full License 


\section{Abstract}

Background: Strong nuclear expression of TFE3 protein resulting from gene fusion has been reported in some neoplasms. TFE3 amplification has been proven to be a novel mechanism leading to increased protein level only in several cases of perivascular epithelioid cell tumor and renal cell carcinoma. Such rare genetic alteration might be associated with poor prognosis or aggressive course. Herein, we first reported a case of undifferentiated sarcoma with epithelioid features harboring TFE3 amplification.

Case presentation: A 66-year-old woman with a history of chronic lymphocytic leukemia and chemotherapy presented with a $4 \mathrm{~cm}$ palpable nodule in the left lower leg. Magnetic resonance imaging revealed an oval juxtacortical lesion to the anterolateral left tibia. Microscopically, the large epithelioid cells with marked pleomorphism and the small round cells intermingled with each other in a diffuse sheet or a hemangiopericytoma-like vascular growth pattern. Myxoid stromal change was evident focally, imparting a hypocellular appearance. Atypical mitotic figures and lymph node metastasis were identified while tumor necrosis was absent. Immunohistochemically, the tumor was positive for vimentin, TFE3, CD68 and CD34. TFE3 gene amplification was identified by fluorescence in situ hybridization. Surgical resection was performed. The patient was alive without recurrence 8 month after surgery.

Conclusions: The present case might represent a novel entity. Our report expands the scope of tumors carrying TFE3 amplification, and raises more attention to this rare genetic alteration and its association with potential aggressive behavior of the tumor.

\section{Background}

As a number of microphthalmia/transcription factor $\mathrm{E}$ (MiT/TFE) family, the transcription factor E3 (TFE3) protein plays an important role in tumorigenesis ${ }^{1,2}$. Strong nuclear expression of TFE3 protein is characteristically identified in several tumors including alveolar soft part sarcoma (ASPS), perivascular epithelioid cell tumor (PEComas), Xp11.2 renal cell carcinomas, granular cell tumor, and epithelioid haemangioendothelioma ${ }^{3-7}$. The genetic or epigenetic alterations involving TFE3 expression are complicated and have not been fully elucidated. Apart from gene translocation, TFE3 gene amplification has been proven to be an additional, novel mechanism leading to increased TFE3 protein expression in several cases of PEComas ${ }^{8-10}$ and renal cell carcinoma ${ }^{11}$. In this article, we first presented a case of undifferentiated sarcoma with epithelioid features harboring TFE3 amplification, its clinicopathological features, and differential diagnosis.

\section{Case presentation}

A 66-year-old woman presented with a $4 \mathrm{~cm}$ palpable and painful nodule in the left lower leg that was detected approximately 1 month before consultation. The patient was diagnosed with chronic lymphocytic leukemia (CLL) 8 years ago. Clinic staging was not available. Oral chlorambucil was attempted once per week for 4 years, combining with thymalfasin injection twice a month to improve the immune condition. The patient had a good response to therapy with no sign of recurrence or blastic 
transformation. The familial history was uneventful. Magnetic resonance imaging revealed an oval juxtacortical lesion with a well-defined margin to the anterolateral left tibia, measuring $4.9 \times 2.4 \times 1.2 \mathrm{~cm}$. Periosteal reaction of the tibia was identified, indicating its aggressiveness. Neither cortical erosion nor marrow infiltration was observed (Figure.1A-E). Surgical resection was performed.

Grossly, the resected specimen consisted of multiple fragments with gray or white on cut surface, measuring $6 \times 3 \times 2 \mathrm{~cm}$ in size. Microscopically, the well-circumscribed but unencapsulated lesion displayed variable cellularity. Two morphologically distinct types of tumor cells intimately intermingled with each other and were arranged in a diffuse sheet or a hemangiopericytoma-like vascular pattern (Figure.2A). One type of tumor cells was the large epithelioid cells with remarkable cytologic atypia. The abundant eosinophilic cytoplasm was homogeneous, granular, or vacuolated. The appearance of large hyperchromatic nuclei ranged from oval to polygonal and centric to eccentric. Multinucleated giant cells with up to three to four nuclei per cell, were not uncommon. Prominent eosinophilic nucleoli and intranuclear inclusions were observed (Figure.2B). The other type of tumor cells was the small round cells with an oval or irregular nucleus. The cytoplasm was scant without a distinct cellular boundary. Myxoid stromal change was evident focally, imparting a relative hypocellular appearance (Figure.2C). Small- to medium-size blood vessels were scattered throughout the lesion. Lymphocytic infiltration was identified and was prominent along the perivascular spaces. Atypical mitotic figures were abundant in the large epithelioid tumor cells but less remarkable in the small round cells (Figure.2B). Tumor necrosis was absent. Tumor metastasis was present in one lymph node (Figure.2D). Immunohistochemically, both the components were diffusely positive for vimentin, TFE3 (Figure.3A), and CD68 (Figure.3B), partially positive for CD34 (Figure.3C), and retained the nuclear expression of INI1. The tumor cells were negative for CK, desmin, myogenin, MyoD1, SMA, HMB45, MelanA, MiTF, STAT6, CDK4, MDM2, S-100 protein, CD31, FLI-1, CD163 (Additional file 1: Figure S1), and MPO. The Ki-67 index was up to $60 \%$ in the hot spot area (Figure.3D). Fluorescence in situ hybridization (FISH) analysis with TFE3 Probe was breakapart designed to detect gene rearrangement and could be also used for the detection of polyploidy or target gene amplification. In normal cells of the present case (female), the copy of TFE3 gene is 2 . But in tumor cells, TFE3 Probe show more copies, and the average copy number in each cell is 7 . Of which, the number of Green probe and Orange probe is equal in each amplified cell. One hundred consecutive nuclei were counted, 1R1G1F accounted for $1 \%$, and the polyploid proportion was $68 \%$ (Figure.4A). Gene fusion of TFE3 with PRCC, ASPSCR1 or NONO was not identified by FISH with gene fusion probe. One hundred consecutive nuclei were counted, $1 \mathrm{R} 1 \mathrm{G} 1 \mathrm{~F}$ accounted for $1 \%, 2 \%$ and $3 \%$, the polyploid proportion was $68 \%, 65 \%$ and $61 \%$, respectively (Figure.4B-D). Therefore, no TFE3 rearrangement but TFE3 gene amplification was identified in the present case. We made the diagnosis of undifferentiated sarcoma with epithelioid features harboring TFE3 amplification. The patient was alive and well at 10 month follow-up information after surgery by radiological examination.

\section{Discussions And Conclusions}

Based on the morphological and genetic features, PEComa is a strong consideration for the diagnosis. PEComas can be composed of epithelioid and spindle cells arranged in a hemangiopericytoma-like 
vascular pattern. TFE3 is positively expressed in a number of PEComas resulting from gene fusion ${ }^{12}$. TFE3 gene amplification, a characteristic finding in the present case, has also been documented in three cases of PEComas; all of these PEComas were found in adults and showed predominant or pure epithelioid morphology. Among these, two cases displayed marked atypical large cells with abundant eosinophilic cytoplasm, nuclear anaplasia, and multipolar mitotic figures, sharing histological overlaps with the present case. However, tumor cells in PEComas are commonly positive for melanocytic and smooth muscle markers; all the three cases were positive for Melan-A and actin/SMA, two were positive for HMB45 ${ }^{8-10}$, whereas none of Melan-A, HMB45 and actin/SMA were expressed in the present case. Therefore, evidence for classifying the tumor as PEComa is insufficient.

Several sarcomas should also be taken into consideration owing to their morphologic resemblance, including solid variant of ASPS, epithelioid sarcoma, epithelioid angiosarcoma, and epithelioid rhabdomyosarcoma. ASPS typically is composed of large eosinophilic cells in nest or pseudoalveolar growth pattern delineated by fibrous septa. In solid variant of ASPS, tumor cells arrange in a diffuse sheet growth pattern without conspicuous nesting, fibrous septa, or dilated sinusoidal vascular channels. Increased cytologic pleomorphism and nuclear pleomorphism are uncommon but have been described ${ }^{13}$. ASPS demonstrates nuclear expression of TFE3, resulting from the oncogenic fusion or rearrangement of $\mathrm{TFE}^{5}$. However, such characteristic chromosomal translocation was not detected by FISH in the present tumor. The intracytoplasmic accumulation of rod-shaped crystals, which is another specific character of ASPS, could be found in a majority of the cases, was not identified. Both epithelioid sarcoma and epithelioid angiosarcoma are composed of diffusely arranged large cells with abundant eosinophilic cytoplasm, vesicular nuclei, and prominent nucleoli. As for epithelioid sarcoma, especially in the proximaltype, pleomorphism is prominent ${ }^{14}$. It is one of the few mesenchymal neoplasms that metastasize to lymph nodes. CD 34 is expressed in $50 \%$ of cases. However, epithelioid sarcoma is positive for CK and EMA, and usually loss of nuclear INI1 expression ${ }^{15}$. Epithelioid angiosarcoma presents irregular vascular spaces lined by protuberant epithelioid tumor cells. Endothelial differentiation should be demonstrated by the expression of endothelial markers such as CD31, CD34, ERG and FLI- $1^{13}$. In contrast to the obvious cytologic pleomorphism in the present case, cells and nuclei in epithelioid rhabdomyosarcoma tend be relatively uniform in size. Skeletal muscle differentiation should be proven based on immunostaining for myogenin and myoD $1^{16}$. Therefore, the diagnoses of ASPS, epithelioid sarcoma, epithelioid angiosarcoma, and epithelioid rhabdomyosarcoma were easily excluded.

Immunochemical panels were used to explore possible differentiation of the present tumor. Apart from vimentin, TFE3, and INI-1, only CD68 and CD34 were positive. Because of the non-specificity, whether such immunophenotype would be a diagnostic feature remained to be illuminated. CD68 expression might indicate histiocytic proliferation and be found in fibrous histiocytomas and granular cell tumor ${ }^{13}$. However, the tumor cells were negative for CD163, a biomarker that is truly histocyte specific superior to CD68, rendering the evidence for histiocytic differentiation weak. CD34 is a non-specific biomarker that should always be used in conjunction with morphology and other markers. Diffuse expression is usually significant; weak or focal expression is often nonspecific. Tumors with fibroblastic/ myofibroblastic or 
peripheral nerve sheath differentiation might be positive for CD34. Most of them should simultaneously express other more specific markers, such as SMA and/or desmin, and S-100 protein respectively. Other markers explored in the present case include MiTF, STAT6, CDK4, MDM2 and MPO, all of which were negative, demonstrating the undifferentiated nature of the tumor.

TFE3 immunoreactivity has been identified in several neoplasms, ranging from weak to intense expression levels (Table 1). The most common chromosomal abnormalities involving TFE3 are translocations and rearrangements, and are among the earliest reported gene fusion in tumorigenesis ${ }^{17,18}$. TFE3 gene fusion can occur with different partners, such as PRCC, ASPSCR1, SFPQ/PSF, and NONO, all of which provide active gene promoters, and therefore, lead to higher levels of TFE3 fusion proteins than wild-type TFE3 ${ }^{5,19,20}$. Apart from ASPS, PEComas, and renal cell carcinoma, which were most extensively studies, epithelioid hemangioendothelioma with YAP1-TFE3 gene fusion ${ }^{21}$ and malignant chondroid syringoma with PHF1-TFE3 gene fusion ${ }^{22}$ were also identified respectively. Although nuclear immunoreactivity for TFE3 protein by immunohistochemistry staining was initially considered as a highly sensitive and specific diagnostic tool for neoplasms bearing TFE3 gene fusions ${ }^{23}$, subsequent FISH analysis demonstrated that there was no relationship between immunoreactivity and gene fusion ${ }^{24,25}$. For instance, although TFE3 was positive in $53 \%-91 \%$ of granular cell tumors and $93.5 \%$ of desmoid-type fibromatosis, gene rearrangement was absent according to FISH analysis, whether the immunohistochemical staining was weak or strong $24,26,27$. Therefore, molecular and/or cytogenetic analysis should be performed to avoid false positive staining ${ }^{28}$. TFE3 gene amplification has only been identified in several cases. Apart from PEComas, it has also been confirmed in four cases of renal cell carcinomas with moderate to strong nuclear expression of TFE $3^{11}$. TFE3 is located on X-chromosome, aneuploidy for $X$-chromosome was detected and resulted in increasing TFE3 copy numbers ${ }^{10,11}$. In the present case, we also inferred that it was the $X$ polyploidy that caused TFE3 gene amplified. An interesting finding is that such genetic alteration might be associated with aggressive biological behavior $^{8-11}$. As for renal cell carcinoma, patients with TFE3 amplification exhibited a significantly poorer cancer-specific survival rate than those with translocation ${ }^{11}$. As for PEComas, distant metastasis and recurrence were documented ${ }^{8-10}$. In the present case, tumor aggressiveness has been suggested by radiological examination, and one lymph node metastasis was identified.

The latency time between the diagnosis of CLL and the present sarcoma was 8 years. There is no strong evidence of the relationship between these two tumors in this patient. Studies have shown increased risks of second malignancies after CLL. Langerhans cell sarcoma ${ }^{29}$, myeloid sarcoma ${ }^{30}$, and histiocytic/dendritic cell sarcomas ${ }^{31}$ would transdifferentiate from CLL. Skin neoplasm was also reported preceding the diagnosis CLL, including malignant melanoma ${ }^{32}$, Kaposi sarcoma ${ }^{33-35}$, Merkel cell carcinoma, malignant fibrous histiocytoma, dermatofibrosarcoma protuberans, sebaceous carcinoma ${ }^{36}$, and leiomyosarcoma ${ }^{37}$. However, the morphological and immunochemical features of the present case did not support any of these neoplasms. The most common adverse effect of chlorambucil is myelosuppression. One conjunctival Kaposi's sarcoma was developed in one patient with sympathetic 
ophthalmia treated with high-dose, short-term chlorambucil therapy ${ }^{38}$. No study has documented undifferentiated sarcoma resulting from chlorambucil therapy.

In conclusion, we present a case of undifferentiated sarcoma with characteristic genetic alteration. Even comprehensive immunohistochemistry and molecular examination could not help in classifying the tumor under any of the existing soft tissue tumor classification. Therefore, we designated it as epithelioid undifferentiated sarcoma with TFE3 amplification. Our report indicated TFE3 amplification as an additional chromosomal abnormality might result in increased expression of protein, and suggested the possible relationship between the genetic alteration and biological behavior of tumor.

\section{Declarations}

\section{Ethics approval and consent to participate}

The patients provided informed consent. The study was approved by the Ethics Committee of Clinical Research and Experimental Animal of the First Affiliated Hospital, Sun Yat-Sen University.

\section{Consent for publication}

Written informed consents for publication of clinical details and clinical images were obtained from the patient. A copy of the consent form is available for review by the Editor of this journal.

\section{Availability of data and materials}

Please contact author for data requests.

\section{Competing interests}

The authors declare that they have no competing interests.

\section{Funding}

None.

\section{Authors' contributions}

Yuejiao Lang and Xiaojuan Li contributed equally to this work. Yuejiao Lang wrote the manuscript. Xiaojuan Li collected and analyzed the pathological data. Shaoyu Chen performed and analyzed FISH. Pei Xiang analyzed the radiological examination and wrote the coincident part. Anjia Han analyzed the data and revised the manuscript.

\section{Acknowledgements}

Not applicable. 


\section{Abbreviations}

ASPS: alveolar soft part sarcoma;

CLL: chronic lymphocytic leukemia;

FISH: fluorescence in situ hybridization;

MiT: microphthalmia;

PEComas: perivascular epithelioid cell tumor;

TFE3: the transcription factor E3

\section{References}

1. Hemesath TJ, Steingrímsson E, McGill G, et al. Microphthalmia, a critical factor in melanocyte development, defines a discrete transcription factor family. Genes \& development. 1994;8(22):277080.

2. Haq R, Fisher DE. Biology and clinical relevance of the micropthalmia family of transcription factors in human cancer. Journal of clinical oncology : official journal of the American Society of Clinical Oncology. 2011;29(25):3474-82.

3. Sandberg A, Bridge J. Updates on the cytogenetics and molecular genetics of bone and soft tissue tumors: alveolar soft part sarcoma. Cancer Genet Cytogenet. 2002;136(1):1-9.

4. Folpe AL, Mentzel T, Lehr HA, et al. Perivascular epithelioid cell neoplasms of soft tissue and gynecologic origin: a clinicopathologic study of 26 cases and review of the literature. Am J Surg Pathol. 2005;29(12):1558-75.

5. Argani P, Antonescu CR, Illei PB, et al. Primary renal neoplasms with the ASPL-TFE3 gene fusion of alveolar soft part sarcoma: a distinctive tumor entity previously included among renal cell carcinomas of children and adolescents. Am J Pathol. 2001;159(1):179-92.

6. Liu Y, Zheng Q, Wang C, et al. Granular cell tumors overexpress TFE3 without gene rearrangement: Evaluation of immunohistochemistry and break-apart FISH in 45 cases. Oncol Lett. 2019;18(6):635560.

7. Mohamed AD, Tremblay AM, Murray GI, et al. The Hippo signal transduction pathway in soft tissue sarcomas. Biochim Biophys Acta. 2015;1856(1):121-9.

8. Argani P, Aulmann S, Illei PB, et al. A distinctive subset of PEComas harbors TFE3 gene fusions. Am J Surg Pathol. 2010;34(10):1395-406.

9. Jimbo N, Nishigami T, Noguchi M, et al. Hepatic angiomyolipomas may overexpress TFE3, but have no relevant genetic alterations. Hum Pathol. 2017;61:41-8.

10. Wang $\mathrm{H}$, Zhan $\mathrm{H}, \mathrm{Yao} Z$, et al. Malignant renal epithelioid angiomyolipoma with TFE3 gene amplification mimicking renal carcinoma. Clin Nephrol Case Stud. 2018;6:11-5. 
11. Macher-Goeppinger S, Roth W, Wagener N, et al. Molecular heterogeneity of TFE3 activation in renal cell carcinomas. Mod Pathol. 2012;25(2):308-15.

12. Thway K, Fisher C. PEComa: morphology and genetics of a complex tumor family. Ann Diagn Pathol. 2015;19(5):359-68.

13. Matthew R.Lindberg DL, Jerad M. Gardner, David S. Cassarino, Kandi Stallings-Archer. Diagnostic Pathology: Soft Tissue Tumors. 2nd ed. Canada: Elsevier; 2016.

14. Guillou L, Wadden C, Coindre JM, et al. "Proximal-type" epithelioid sarcoma, a distinctive aggressive neoplasm showing rhabdoid features. Clinicopathologic, immunohistochemical, and ultrastructural study of a series. Am J Surg Pathol. 1997;21(2):130-46.

15. Hornick JL, Dal Cin P, Fletcher CD. Loss of INI1 expression is characteristic of both conventional and proximal-type epithelioid sarcoma. Am J Surg Pathol. 2009;33(4):542-50.

16. Jo VY, Marino-Enriquez A, Fletcher CD. Epithelioid rhabdomyosarcoma: clinicopathologic analysis of 16 cases of a morphologically distinct variant of rhabdomyosarcoma. Am J Surg Pathol. 2011;35(10):1523-30.

17. Shipley JM, Birdsall S, Clark J, et al. Mapping the X chromosome breakpoint in two papillary renal cell carcinoma cell lines with a $t(X ; 1)(p 11.2 ; q 21.2)$ and the first report of a female case. Cytogenetics and cell genetics. 1995;71(3):280-4.

18. Sidhar SK, Clark J, Gill S, et al. The $t(X ; 1)(p 11.2 ; q 21.2)$ translocation in papillary renal cell carcinoma fuses a novel gene PRCC to the TFE3 transcription factor gene. Hum Mol Genet. 1996;5(9):1333-8.

19. Clark J, Lu YJ, Sidhar SK, et al. Fusion of splicing factor genes PSF and NonO (p54nrb) to the TFE3 gene in papillary renal cell carcinoma. Oncogene. 1997;15(18):2233-9.

20. Weterman MA, Wilbrink M, Geurts van Kessel A. Fusion of the transcription factor TFE3 gene to a novel gene, $P R C C$, in $t(X ; 1)(p 11 ; q 21)$-positive papillary renal cell carcinomas. Proceedings of the National Academy of Sciences of the United States of America. 1996;93(26):15294-8.

21. Antonescu CR, Le Loarer F, Mosquera JM, et al. Novel YAP1-TFE3 fusion defines a distinct subset of epithelioid hemangioendothelioma. Genes Chromosomes Cancer. 2013;52(8):775-84.

22. Panagopoulos I, Gorunova L, Lund-Iversen M, et al. Fusion of the Genes PHF1 and TFE3 in Malignant Chondroid Syringoma. Cancer Genomics Proteomics. 2019;16(5):345-51.

23. Argani $P$, Lal $P$, Hutchinson $B$, et al. Aberrant nuclear immunoreactivity for TFE3 in neoplasms with TFE3 gene fusions: a sensitive and specific immunohistochemical assay. Am J Surg Pathol. 2003;27(6):750-61.

24. Zhou L, Xu H, Zhou J, et al. Nuclear TFE3 expression is a diagnostic marker for Desmoid-type fibromatosis. Diagn Pathol. 2019;14(1):34.

25. Flucke U, Vogels RJ, de Saint Aubain Somerhausen N, et al. Epithelioid Hemangioendothelioma: clinicopathologic, immunhistochemical, and molecular genetic analysis of 39 cases. Diagn Pathol. 2014;9:131. 
26. Chamberlain BK, McClain CM, Gonzalez RS, et al. Alveolar soft part sarcoma and granular cell tumor: an immunohistochemical comparison study. Hum Pathol. 2014;45(5):1039-44.

27. Schoolmeester JK, Lastra RR. Granular cell tumors overexpress TFE3 without corollary gene rearrangement. Hum Pathol. 2015;46(8):1242-3.

28. Rekhi B, Ingle A, Agarwal M, et al. Alveolar soft part sarcoma 'revisited': clinicopathological review of 47 cases from a tertiary cancer referral centre, including immunohistochemical expression of TFE3 in 22 cases and 21 other tumours. Pathology. 2012;44(1):11-7.

29. Papoudou-Bai A, Vassou A, Marinos L, et al. Concurrent cutaneous localization of Langerhans cell sarcoma and chronic lymphocytic leukemia/small lymphocytic lymphoma in a patient with a history of chronic lymphocytic leukemia/small lymphocytic lymphoma. J Cutan Pathol. 2020;47(2):161-5.

30. Perifanis V, Diamantidis MD, Chalvatzi K, et al. Concurrent presentation of nodal myeloid sarcoma and bone marrow chronic lymphocytic leukemia/small lymphocytic lymphoma: a unique association. International journal of hematology. 2014;99(4):508-12.

31. Shao H, Xi L, Raffeld M, et al. Clonally related histiocytic/dendritic cell sarcoma and chronic lymphocytic leukemia/small lymphocytic lymphoma: a study of seven cases. Mod Pathol. 2011;24(11):1421-32.

32. Morton LM, Curtis RE, Linet MS, et al. Second malignancy risks after non-Hodgkin's lymphoma and chronic lymphocytic leukemia: differences by lymphoma subtype. Journal of clinical oncology : official journal of the American Society of Clinical Oncology. 2010;28(33):4935-44.

33. Kose F, Kocer NE, Sumbul AT, et al. Kaposi's Sarcoma following Chronic Lymphocytic Leukemia: A Rare Entity. Case reports in oncology. 2012;5(2):271-4.

34. Vučinić D, Dekanić A, Zamolo G, et al. Kaposi's sarcoma in an HIV-negative chronic lymphocytic leukemia patient without immunosuppressive therapy: A case report. SAGE Open Med Case Rep. 2018;6:2050313x18799239.

35. Hacioglu MB, Sahin S, Karatas F, et al. A rare coexistence--Chronic lymphocytic leukemia and Kaposi sarcoma: Case report and review of the literature. Journal of cancer research and therapeutics. 2015;11(4):954-6.

36. Brewer JD, Shanafelt TD, Call TG, et al. Increased incidence of malignant melanoma and other rare cutaneous cancers in the setting of chronic lymphocytic leukemia. International journal of dermatology. 2015;54(8):e287-93.

37. Polat AK, Soran A, Kanbour-Shakir A, et al. Subcutaneous Leiomyosarcoma Metastasized to the Lymph Nodes Involved with Small Lymphocytic Lymphoma / Chronic Lymphocytic Leukemia. Turk patoloji dergisi. 2017;33(3):244-7.

38. Patel SS, Dodds EM, Echandi LV, et al. Long-term, drug-free remission of sympathetic ophthalmia with high-dose, short-term chlorambucil therapy. Ophthalmology. 2014;121(2):596-602.

\section{Tables}


Table 1. TFE3-related tumors

\begin{tabular}{|c|c|c|c|}
\hline Tumor type & Distribution rates $^{a}$ & $\begin{array}{l}\text { Expression } \\
\text { levels }\end{array}$ & Gene fusion \\
\hline $\begin{array}{l}\text { alveolar soft part } \\
\text { sarcoma } 40,41\end{array}$ & NA & $\begin{array}{l}\text { weak to } \\
\text { strong }\end{array}$ & $\begin{array}{l}\text { ASPSCR1-TFE3; DVL2-TFE3; } \\
\text { PRCC-TFE3; HNRNPH3-TFE3 }\end{array}$ \\
\hline $\begin{array}{l}\text { perivascular epithelioid } \\
\text { cell tumor }{ }^{42-44}\end{array}$ & NA & $\begin{array}{l}\text { weak to } \\
\text { strong }\end{array}$ & $\begin{array}{l}\text { NONO-TFE3; SFPQ/PSF-TFE3; } \\
\text { DVL2-TFE3; }\end{array}$ \\
\hline $\begin{array}{l}\text { Xp11.2 renal cell } \\
\text { carcinomas }^{5,20,21,42,45,46}\end{array}$ & NA & $\begin{array}{l}\text { weak to } \\
\text { strong }\end{array}$ & $\begin{array}{l}\text { ASPSCR1-TFE3; NONO-TFE3; } \\
\text { PRCC-TFE3; SFPQ/PSF-TFE3; } \\
\text { CLTC-TFE3; DVL2-TFE3 }\end{array}$ \\
\hline $\begin{array}{l}\text { epithelioid } \\
\text { hemangioendothelioma } 22\end{array}$ & NA & strong & YAP1-TFE3 \\
\hline $\begin{array}{l}\text { malignant chondroid } \\
\text { syringoma }\end{array}$ & $100 \% \otimes 1 / 1 \rrbracket$ & strong & PHF1-TFE3 \\
\hline granular cell tumors 27,28 & $\begin{array}{l}53 \% \\
(24 / 45)-91 \% \bigotimes 10 / 11 \rrbracket\end{array}$ & $\begin{array}{l}\text { weak to } \\
\text { strong }\end{array}$ & Not identified \\
\hline $\begin{array}{l}\text { desmoid-type } \\
\text { fibromatosis }\end{array}$ & $93.5 \%(43 / 46)$ & $\begin{array}{l}\text { moderate } \\
\text { to strong }\end{array}$ & Not identified \\
\hline nodular fasciitis ${ }^{25}$ & $42.9 \% \rrbracket 6 / 14 \rrbracket$ & weak & NA \\
\hline $\begin{array}{l}\text { gastrointestinal stromal } \\
\text { tumor }^{25}\end{array}$ & $40 \% \rrbracket 4 / 10 \rrbracket$ & weak & NA \\
\hline scar tissue samples ${ }^{25}$ & $25 \% \otimes 1 / 4 \rrbracket$ & weak & NA \\
\hline paragangliomas $^{29}$ & $75 \%(3 / 4)$ & strong & NA \\
\hline $\begin{array}{l}\text { adrenocortical } \\
\text { carcinoma }^{29}\end{array}$ & $66.6 \%(1 / 3)$ & NA & NA \\
\hline $\begin{array}{l}\text { solid pseudopapillary } \\
\text { neoplasms }{ }^{47}\end{array}$ & $74.7 \% \rrbracket 68 / 91 \rrbracket$ & $\begin{array}{l}\text { weak to } \\
\text { strong }\end{array}$ & NA \\
\hline
\end{tabular}

${ }^{a}$ Data presented as positive percentage (number positive/number tested).

NA: not available.

\section{Figures}



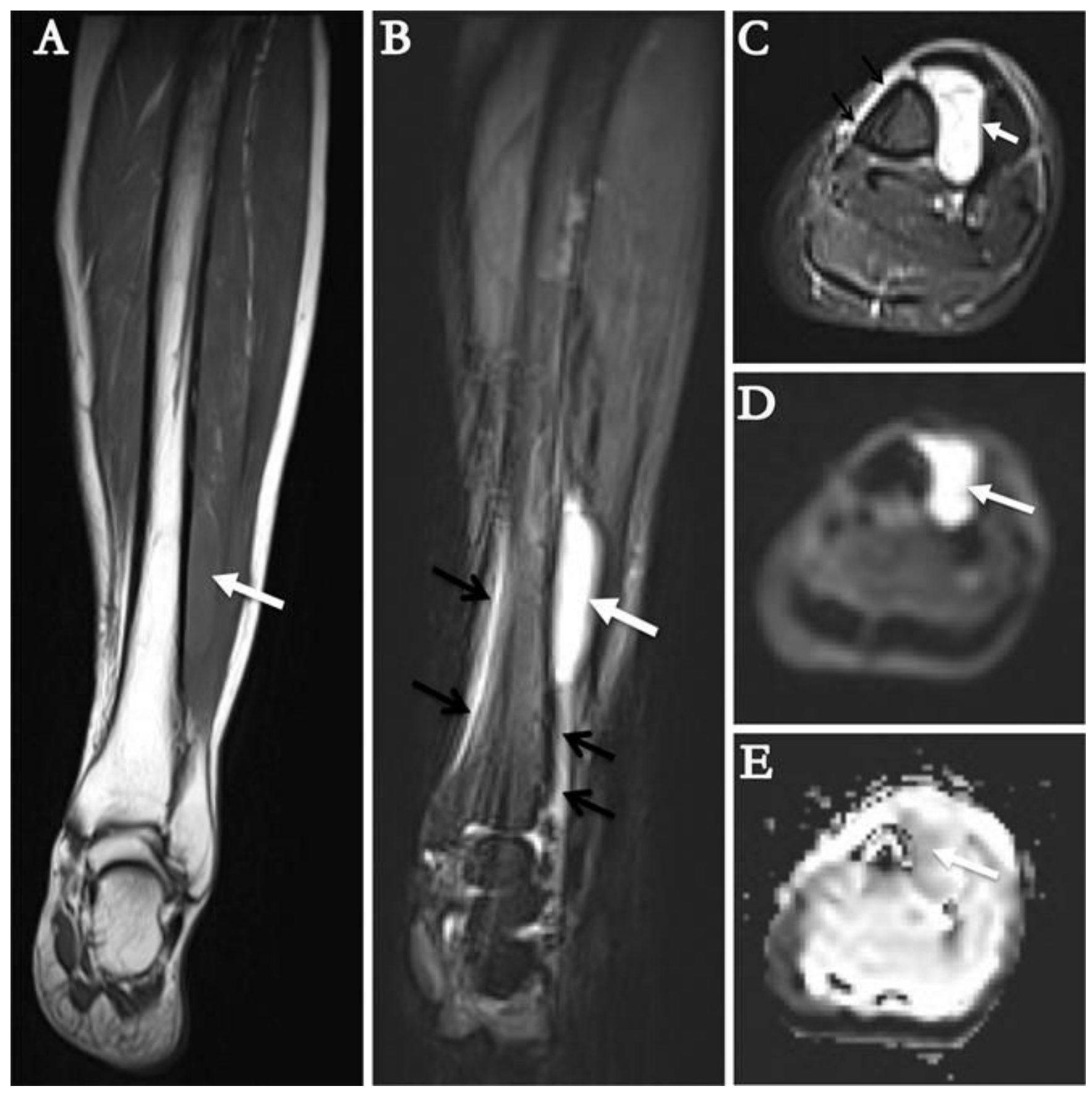

\section{Figure 1}

Radiological characteristics illustrated by magnetic resonance imaging. The lesion (white arrows) appeared iso-intense on coronal T1WI (A), hyper-intense on coronal (B) and axial (C) T2WI with fatsuppression. It appeared hyper-intense on diffusion-weighted image ( $b=800 \mathrm{~s} / \mathrm{mm} 2)(D)$ with corresponding decreased apparent diffusion coefficient values on apparent diffusion coefficient map (E), indicating diffusion restriction. The periosteal reaction of tibia was noted on T2WI with fat-suppression (black arrows on B and C). 

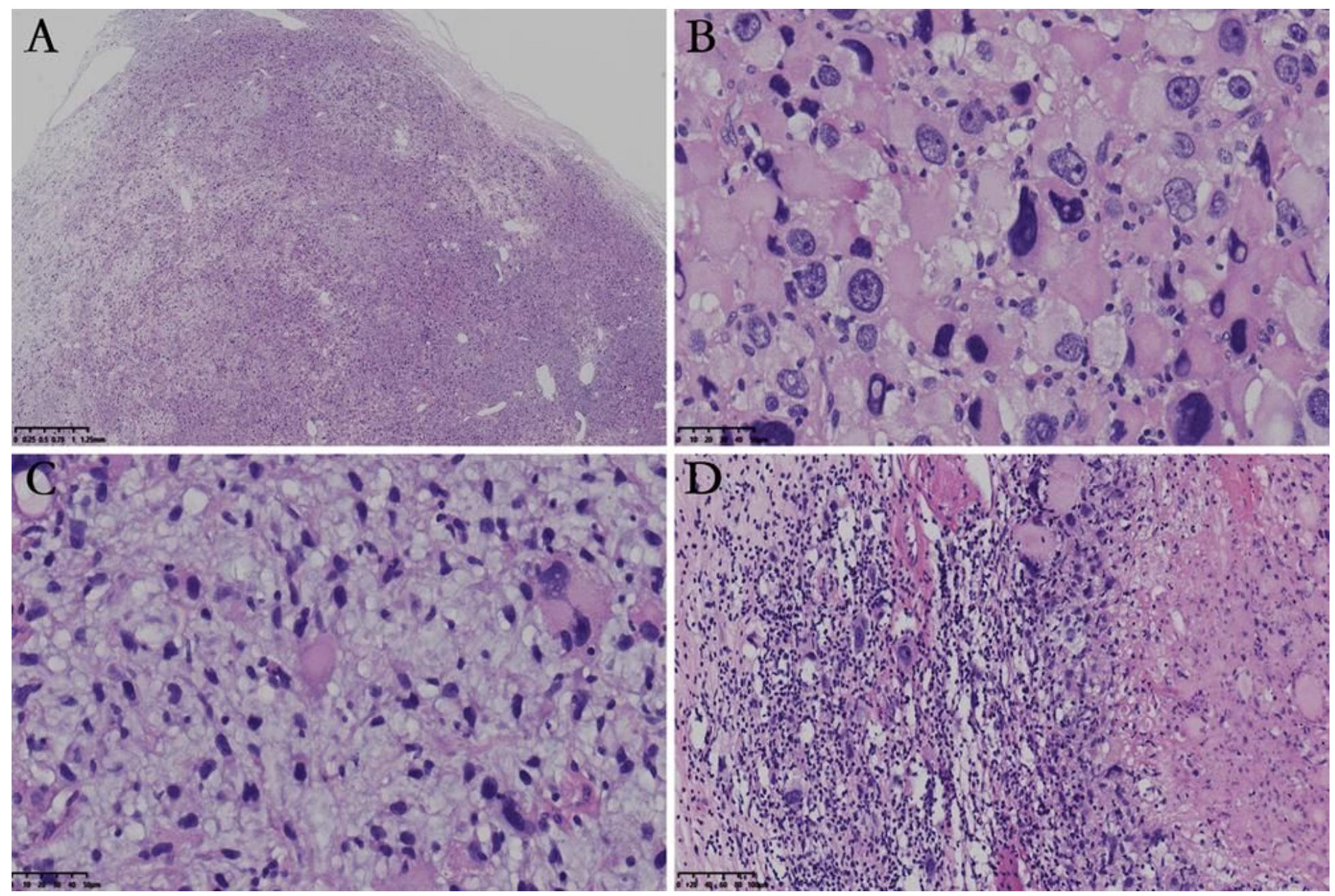

Figure 2

Histological characteristics of the lesion. (A)The well-circumscribed lesion was unencapsulated with variable cellularity. (B)Large epithelioid tumor cells with marked nuclear pleomorphism arranged in a diffuse sheet pattern. Atypical mitotic figures were identified. (C)Small bland cells bear oval or irregular nuclei and scant cytoplasm, with large epithelioid cells in between. Myxoid stromal change was prominent. (D) Metastasis was identified in one lymph node. 

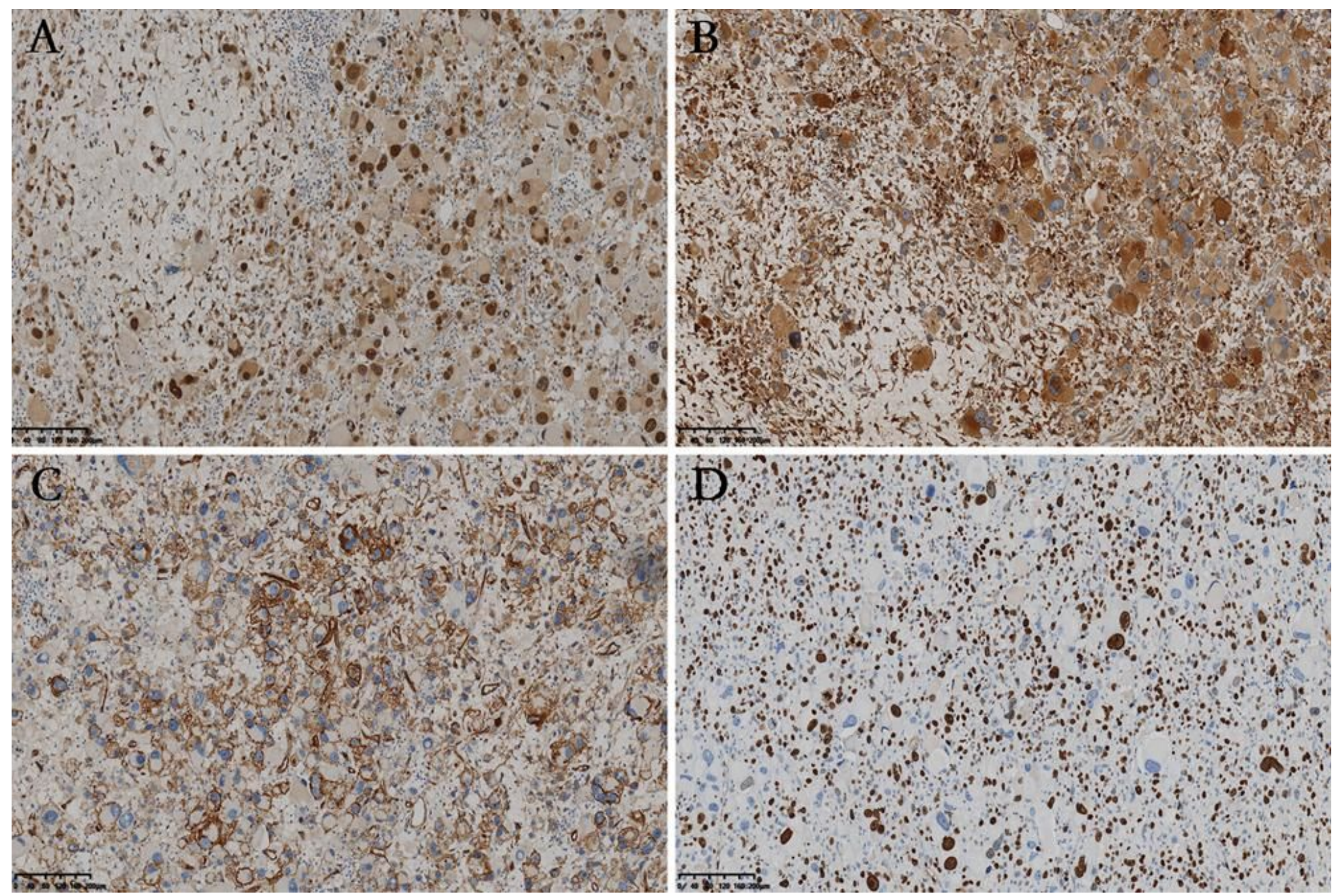

\section{Figure 3}

Immunohistochemical characteristics of the lesion. The tumor cells exhibited diffuse positive reaction for TFE3 (A) and CD68(B), and partially positive reaction for CD34(C). The Ki-67 index was up to $60 \%$ in the hot $\operatorname{spot}(\mathrm{D})$. 

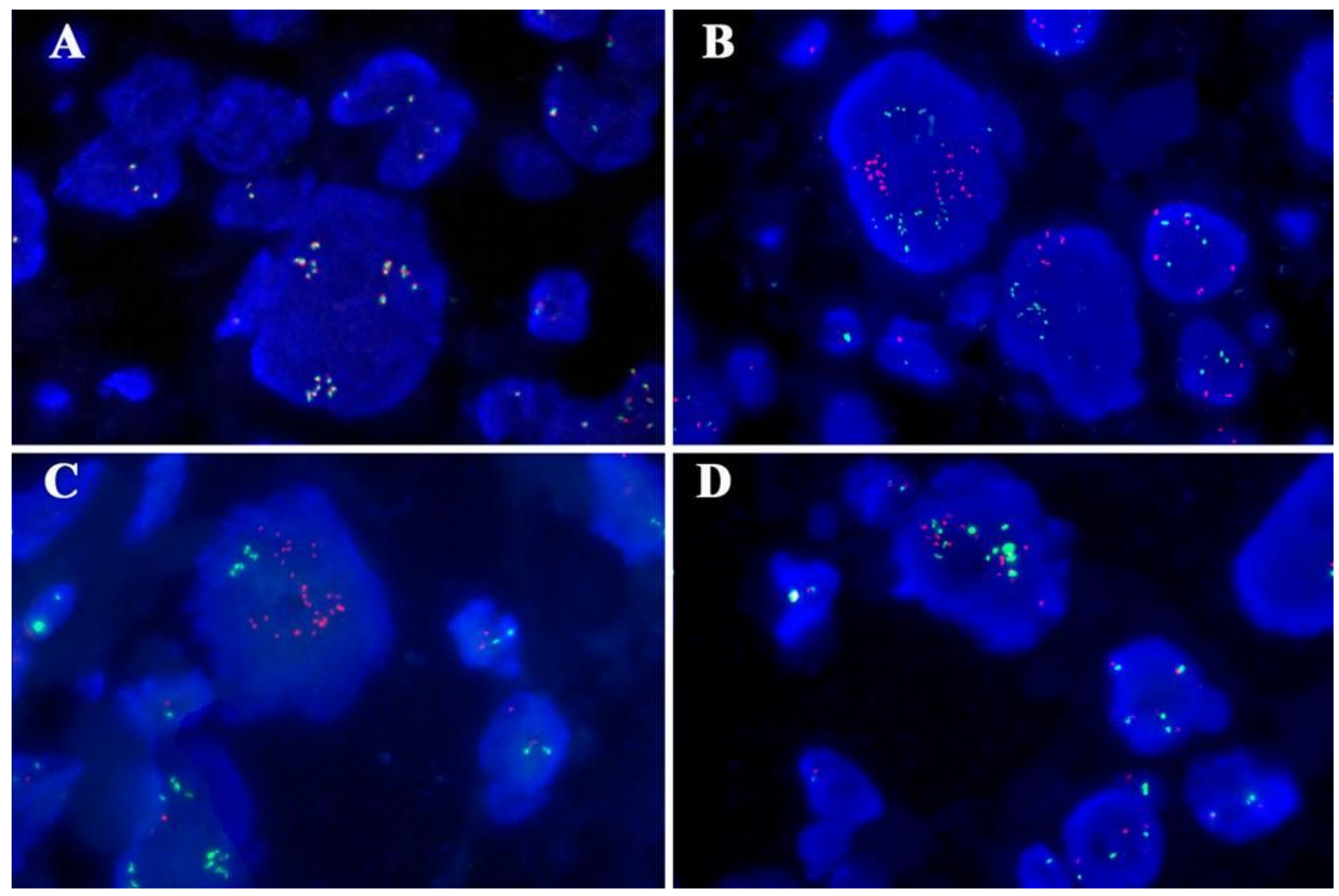

\section{Figure 4}

Genetic characteristics of the lesion. (A) TFE3 break-apart probe showed no TFE3 rearrangement but TFE3 gene amplification by FISH. The TFE3 probe contains a $627 \mathrm{~kb}$ probe labeled in green, which lies proximal to the TFE3 gene that located at Xp11.2 region, and a $637 \mathrm{~kb}$ probe labeled in orange extends distally from the TFE3 gene. (B-D) Gene fusion of TFE3 with PRCC(B), ASPSCR1(C) or NONO(D) was not identified by FISH with gene fusion probe. Green, the 5'- terminal region of the TFE3 gene; orange, the 3'terminal region of the PRCC/ASPSCR1/NONO gene, respectively.

\section{Supplementary Files}

This is a list of supplementary files associated with this preprint. Click to download.

- CAREchecklist.pdf 